\title{
Reseña / Extensión crítica: construcción de una universidad en contexto. Sistematizaciones de experiencias de gestión y territorio de la Universidad Nacional de Rosario
}

Juan Manuel Medina y Humberto Tommasino (2018).

Rosario: UNR Editora. ISBN 978-987. 702-254-4.

Ebook: https://drive.google.com/file/d/113Q_5BhnBh

V1m9hLREV1w3YA3SRL2VwJ/view

Por Daniel de Michele

Universidad Nacional de Entre Ríos, Argentina. demichele@fcs.uner.edu.ar

\section{Investigación y extensión universitaria / Reseña de libros}

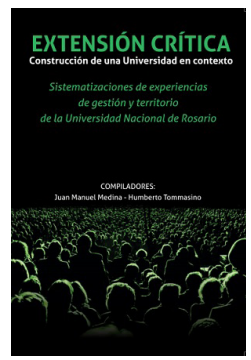

"He venido a hablar de cosas imposibles

porque de los posible se sabe demasiado..."

Silvio Rodríguez

Si está leyendo estas líneas es porque ha decidido interesarse y conocer la intimidad del quehacer de hombres y mujeres — verdaderos arqueólogos sociales- que militan en los espacios de extensión universitaria de la Universidad Nacional de Rosario (UNR).

Ha sido reconocido que la sistematización de experiencias es una metodología originariamente Latinoamericana, enlazada con las ideas de la Pedagogía de la Liberación de Paulo Freire, quien primero balizó el camino de acceso al método (Herout, 2015). En esta obra, los compiladores claramente deciden recorrer este sendero latinoamericano al lado de Freire, Jara, Ghiso, Zúñiga, y varios grupos de trabajo de la Universidad de la República Uruguay.

La idea de generar un proceso de reflexión y recuperación de las experiencias de extensión a partir del 2011 fue interpretada por el grupo de gestión y de trabajo como una necesidad de poner en valor y analizar críticamente estas prácticas, según el mismo equipo lo expresa.

El fin último sería extraer nuevo conocimiento de aquellos procesos y aplicarlo para mejorar y ulteriormente volver al análisis en un espiral continuo.

Durante los 15 meses que tomó al equipo de trabajo esta sistematización, sus excavaciones calaron en las propias prácticas, conviviendo con su cotidianeidad militante, sus pasiones y aprendizajes.

Esta tarea fue simultánea con los debates dados al interior de la UNR sobre los modelos de extensión y de universidad, como también sobre la necesidad de disputar el "espacio académico central".

La resultante de la mixtura del análisis crítico hacia atrás y militancia hacia adelante genera una interfase activa en continuo movimiento, una especie de trabajo de parto. De esa interfase nacen ideas y proyectos nuevos al tiempo que se atenúan los dolores provocados por el esfuerzo necesario para parirlos colectivamente.

He ahí el ciclo vital virtuoso del ideario y la experiencia extensionista.

He ahí un método idóneo: comenzar la tarea de autointerpelación, descubrir por qué hacemos lo que hacemos.

He ahí un trabajo provechoso en tanto es capitalizable para la formación de los militantes de la extensión, sumándose a la caja de herramientas de cada uno. 
Las siguientes experiencias de extensión fueron seleccionadas entre las consideradas más relevantes para ser revisadas:

- Institucionalizar la discapacidad.

- Entretejiendo escenas.

- Abrazando infancias.

- El vinculo en la evaluación presencial.

- Cuando el territorio habla.

- Una bisagra para la educación transformadora.

- Una semana que construimos todo el año.

- Pasantías educativas en la UNR.

- Propuesta de política universitaria.

Es destacable la participación en el proceso de sistematización del equipo de extensión completo de UNR, así como actores sociales y estudiantes involucrados en actividades revisadas.

La resultante de esta amplia participación en el proceso de revisión crítica de las propias practicas ya ha generado tanto un avance teórico individual y colectivo como un incremento en el compromiso de cada uno de los actores con sus tareas.

Los paradigmas de la extensión crítica y la integralidad han funcionado aquí como vigas vertebrales sobre las cuales se apoya la investigación y la producción de conocimiento emergente de la experiencia de sistematización.

Los arquitectos del proyecto son también los albañiles que, desde los cimientos, levantaron los muros y situaron los andamios de este trabajo.

El compromiso y posicionamiento político del equipo se deduce claramente a partir de la crítica que se hace al modelo áulico dominante en nuestras universidades.

La incomodidad que produce la extensión universitaria genuina, al plantear un quiebre con el modelo educativo actual, deja a la vista que algunas de las batallas libradas por los reformistas del '18 habrá que volver a darlas.

Conocida la virtual ausencia de espacios de formación en extensión en nuestras universidades, Extensión Crítica es un producto valioso en cuanto a su aporte teórico a todas las personas (universitarios o no) interesadas en la extensión.

Los compiladores (Tommasino y Medina) conforman un dúo especializado en producción extensionista que ha generado, promovido y participado en múltiples encuentros en Argentina, Uruguay y otros países de América Latina, así como "Escuelas de Verano", actividades en la Unión Latinoamericana de Extensión Universitaria (ULEU) y otras iniciativas.

Debe decirse también que el libro resulta muy oportuno en tanto es contemporáneo, por un lado, con el fin de la gestión de Juan Manuel Medina al frente de la Secretaría de Extensión de UNR, y por el otro, debido a la notable intensificación de la luz del faro que Tommasino permanentemente ha enfocado sobre la "menos oligárquica de las funciones de la universidad" en Latinoamérica toda.

El libro incluye una versión ebook que invita a la descarga gratuita.

Se trata de un texto de cabecera necesario, imprescindible, casi obligatorio para los amigos y enemigos de la extensión universitaria. 